\title{
INVESTIGATING CLIMATE CHANGE BY DIGITAL ANALYSIS OF BLUE ICE EXTENT ON SATELLITE IMAGES OF ANTARCTICA
}

\author{
by
}

Olav Orheim

(Norsk Polarinstitutt, P.O. Box 158, 1330 Oslo Lufthavn, Norway)

and

Baerbel Lucchitta

(U.S. Geological Survey, 2235 North Gemini Drive, Flagstaff, AZ 86001, U.S.A.)

\section{ABSTRACT}

Landsat-5 Thematic Mapper (TM) and SPOT data collected two years apart from an identical area of Dronning (Queen) Maud Land, Antarctica, have been analyzed to detect variations in surface features that may signal climatic change, and to establish a technique that readily identifies such changes. We found that selective principal component analysis (Chavez and Kwarteng 1989), on band ratios of near-IR/green, highlights changes in blue ice areas. The formation and preservation of blue ice is poorly understood, but we suggest that it generally takes longer to increase a blue ice area than to decrease it, and that blue ice extent is most sensitive to changes in accumulation rate. The investigated blue ice area shows a decrease in extent over the two-year period caused by incursion of snow that probably resulted from an increase in accumulation rate. Comparison of two TM images collected 18 days apart shows that transitory snow drifts have little effect on blue ice extent.

\section{INTRODUCTION}

Comparison of satellite images from polar areas, acquired years apart, may yield information that portends possible climate change. As signals giving clues to climate changes are possibly amplified in polar areas, the search for indications of change in Antarctica becomes a critical task. Detecting changes on the ice sheets is facilitated by presence of features that (1) are sensitive to climate change, (2) occur widely so that they reflect changes for most or all of the continent, and (3) can be digitally analyzed from satellite images. We find that Antarctic blue ice fields fulfil these requirements.

In this paper we discuss digital analysis of Landsat and SPOT (Systeme Probatoire d'Observation de la Terre) images that lead to the recognition of changes in blue ice extent that may reflect changes in global climate. Orheim (1977) showed that there was no systematic pattern of change in the century-long ice core records of mass balance and accumulation from Antarctica. Studies of blue ice extent offer a different method for detecting large-scale mass balance changes.

Because of the uncertainties in short-term blue ice variability in Antarctica, determination of changes from a single locality may not yield information of climatic significance. Many analyses, however, that are Antarcticawide and occur at repeated intervals, will yield more significant results. Therefore, the aim of this paper is not to evaluate climatic change from the study of one site, but to demonstrate a technique that will allow the detection of changes in many areas in a rapid and efficient manner.

\section{BLUE ICE}

Blue ice is the term used here to describe the Antarctic phenomenon of snow-free ice, of ten also termed "bare ice". The phenomenon was briefly discussed by Schytt (1961), and has since been described by various authors (e.g. Williams and others, 1983). Examination of the recently published satellite-image atlas of Antarctica (Swithinbank, 1988) shows that blue ice fields are ubiquitous in the nunatak regions of continental Antarctica and in the coastal regions of East Antarctica. They thus fulfil the abovementioned requirement of wide distribution. Field observations and reports from different summer seasons indicate that blue ice fields are characterized by stable appearance, and the following discussion is concerned with changes of such "permanent" blue ice.

\section{Formation of blue ice fields}

Blue ice areas are ablation areas in the classical mass balance sense of having a negative net mass balance $\left(b_{n}<0\right)$. They differ from the generally snow-covered regions of Antarctica by experiencing a combination of low or zero accumulation and significant ablation. The presence of blue ice areas will involve one or more of the following processes:

a) Reduced accumulation from:

(1) wind divergence due to ice topography

(2) wind acceleration due to surface smoothness

(3) reduced snow drift in wind shadow caused by nunataks

b) Increased ablation from:

(1) low surface albedo

(2) long wave radiation from nearby rock surfaces

(3) high air temperatures caused by nearby rock surfaces

(4) high air temperatures caused by adiabatic heating

(5) wind erosion.

The occurrence of blue ice in Antarctica can thus be tied to both external circumstances and the internal properties of the blue ice. External effects are related to geographic location and to direction of ice flow and wind patterns. Internal effects are related to surface properties such as smoothness and low albedo, and represent feedback processes. Blue ice is found upstream, downstream, and down-wind of nunataks. Many upstream sites, inland of nunataks, have been sites for collecting meteorites (Yoshida and others, 1971) that are concentrated by the iceflow (Whillans and Cassidy, 1983).

Air temperatures in the nunatak regions are commonly below $0{ }^{\circ} \mathrm{C}$, and thus the ablation processes usually do not include melting, as opposed to those occurring on glaciers in more temperate latitudes. Instead, ablation is mainly in the form of sublimation; typical rates at $2000 \mathrm{~m}$ elevation are $0.05 \mathrm{~m} \mathrm{year}^{-1}$, and $0.02 \mathrm{~m} \mathrm{month}^{-1}$ in midsummer (e.g. 
Takahashi and others, 1988). Snow accumulation must therefore be very low for blue ice to develop.

Negative mass balance implies ice flow with a net upward emergence velocity. Exposing deeper ice is thus one way of forming blue ice. Another way is by metamorphosis from snow to ice on the surface. The latter process is very slow unless it involves melting and ref reezing of water.

\section{Blue ice and climate}

Blue ice extent may vary because of weather changes, seasonal effects, and climate change. The effects of weather are mainly related to changes in the extent of snow cover on the ice, and depend upon precipitation rate, wind direction and strength. Many such changes will be ephemeral and reverse with a change of weather. These effects will cause noise on the long-term signal, and cannot be eliminated in the analysis of only a few images. But use of many images at repeated intervals will decrease the effects, and patterns of changes may reveal climatic signals.

To what extent the size of blue ice areas varies with the season is poorly known, but they most probably reach a minimum during winter. Observations from temperate latitudes, such as the European Alps and Scandinavia, show that the size of ablation areas of glaciers, i.e. the area of negative mass balance, varies from nearly $0 \%$ to $100 \%$ of the total glacier area in successive years. These variations however are mainly related to ablation by melting during the summer, and differ therefore from the Antarctic situation. Until more knowledge on seasonal variations in blue ice extent is available it seems best to minimize the seasonal effect in the analysis by using images acquired during the same period of the year.

Climatic change will affect the processes causing blue ice extent in several ways. Changes in air temperature will affect energy available for surface ablation, and changes in precipitation and wind direction and strength will affect accumulation. Climatic effects may also affect ice flow patterns, but these are on a time scale beyond the present considerations.

The relations between blue ice extent and climate are not straightforward, however. Increasing a blue ice area can be expected to take a longer time than decreasing it, for the following reasons. The ice field cannot expand onto the nunatak area, so any expansion must take place into adjacent snow fields by the relatively slow processes of either dry snow metamorphosis, or exposure of sub-surface ice. The only exceptions will be cases where blue ice fields expand downhill by refreezing of melt-water. A decrease of the blue ice field, on the other hand, can happen quickly as a result of increased accumulation or possibly of changed wind patterns.

The relations between blue ice extent and climate are also complicated by two conservative feedback processes. First, smooth surfaces hinder drifting snow from settling, primarily because of accelerated wind speeds. Second, low-albedo surfaces cause increased absorption of solar radiation in the summer, an effect which will occur even through a thin layer of snow. Blue ice areas, once formed, tend to persist.

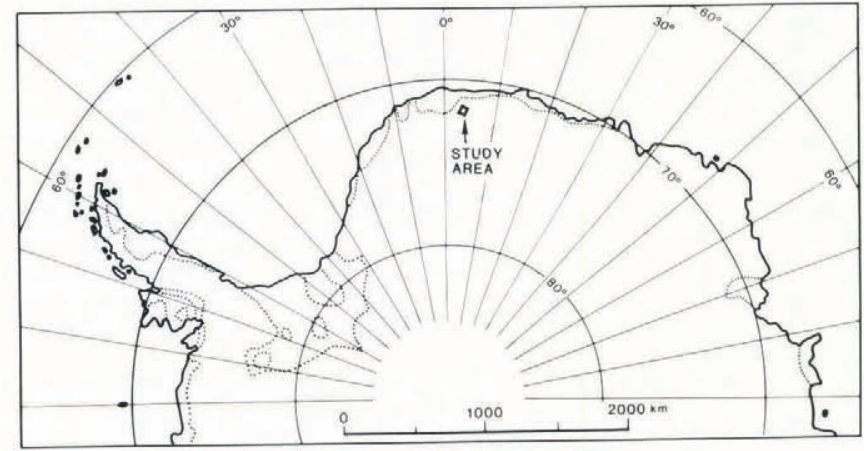

Fig. 1. Index map showing location of images discussed in this paper. The dotted lines show the land boundary of the continent.
It follows from the above that blue ice extent will have varying sensitivity to climatic parameters. Increased accumulation leading to a general decrease in blue ice areas is most readily detected, whereas increased ablation, because of the relatively slow rate of blue ice expansion, is more difficult to detect and requires more permanent changes before it will be noticed. Furthermore, the time lag caused by conservative feed-back processes means that lack of change over many years in blue ice extent cannot be taken as evidence of no climatic change.

The potential warming now expected from the greenhouse gases may lead to increased precipitation, including positive mass balance over Antarctica. The above considerations suggest that studying blue ice extent is a useful method for detecting the increased snow accumulations that might result from such a climatic change.

\section{SATELLITE DATA}

As a demonstration of a technique for detecting blue ice changes, we compared digital data of overlapping scenes from Landsat 5 and SPOT, from Dronning Maud Land, Antarctica (Fig. 1). The scenes are Landsat Nos. 5034407520 and 5036207394, recorded on 8 and 26 February 1985, and SPOT No. 176-680, recorded on 14 February 1987. Thus, the Landsat scenes were acquired only about three weeks apart, whereas the Landsat and SPOT scenes were acquired at a two-year interval.

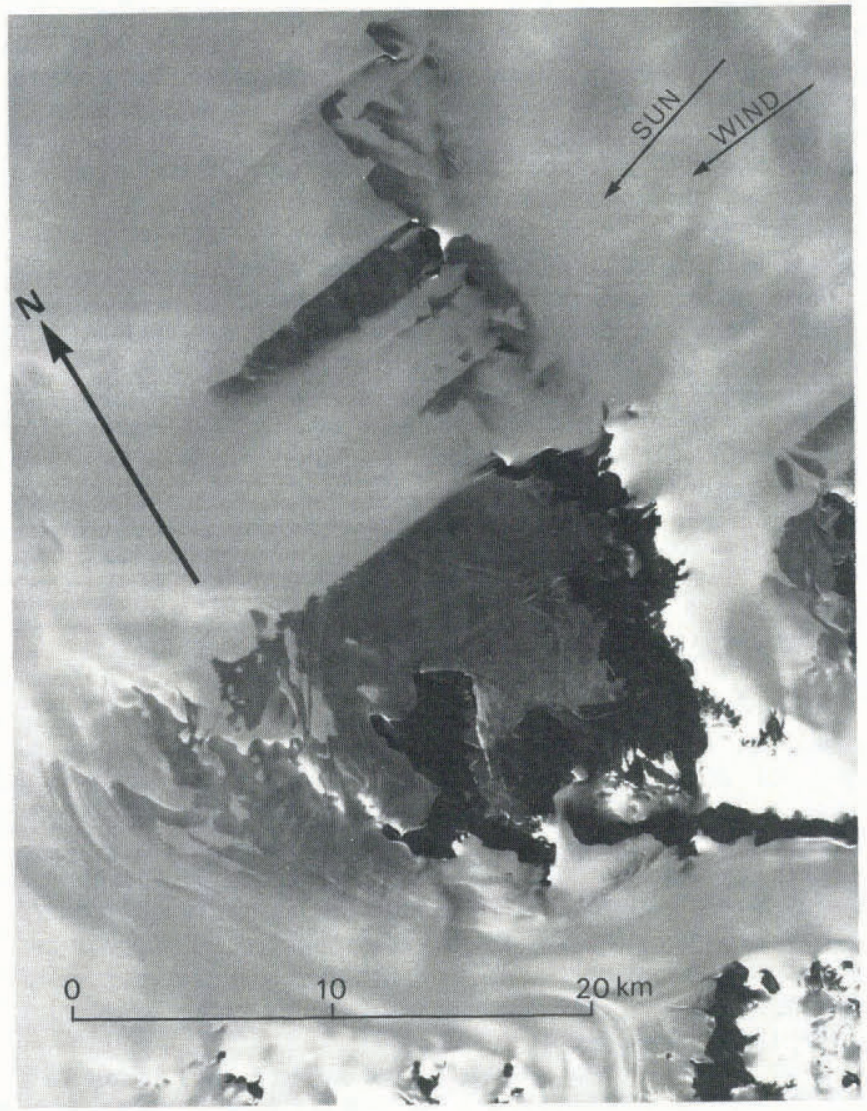

Fig. 2. TM band 4 of Landsat image 5034407520 recorded on 0752 GMT on 8 February 1985 at $22.1^{\circ}$ solar elevation. Scale and north arrow apply also to Figures $3-5$. Linear stretches were applied to bring out details in snow and ice. A prominent blue ice field of $15 \times 10 \mathrm{~km}$ size is shown around Jutulsessen $\left(72^{\circ} \mathrm{S}\right.$, $2^{\circ} 30^{\prime} \mathrm{E}$ ) in lower centre of image. Ground observations show that sublimation here is the main form of mass loss, but that melting occurs at the margins near rock. The ice close to the nunataks flows southwards towards the rocks, which is the main surface slope direction of the blue ice field. The surface slope increases strongly towards the rock margins and is in places around $1: 10$ over a few tens of meters nearest to rock, attesting to very high ablation rates. Small lakes occur at several localities along the boundary between rock and ice. 


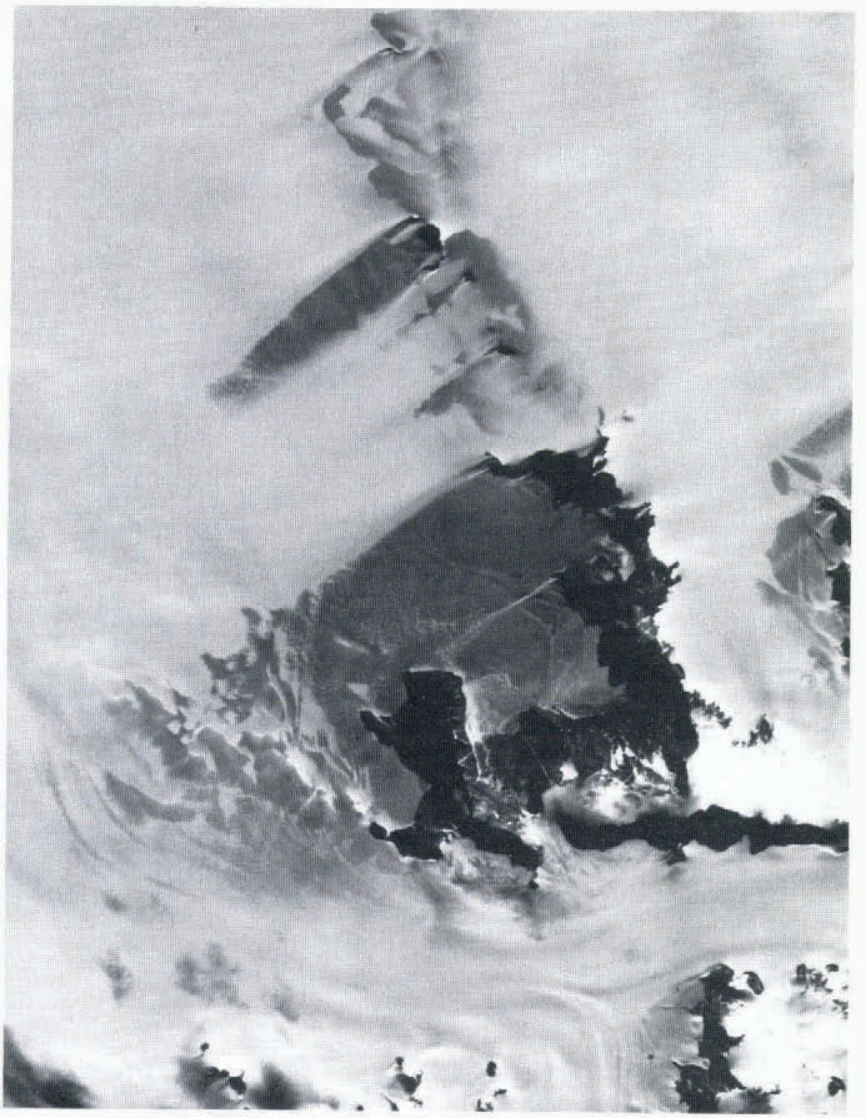

Fig. 3. Band 3 of SPOT image $176-680$, recorded on 14 February 1987 at $24.3^{\circ}$ solar elevation. The image was registered to the Landsat image in Figure 2 and degraded to match the Landsat pixels.

For the comparison we used Landsat Thematic Mapper (TM) bands 2 and 4 and SPOT bands 1 and 3 (respectively green wavelength about $0.5-0.6 \mu \mathrm{m}$, and near-IR wavelength about $0.8-0.9 \mu \mathrm{m})$. These bands were chosen because these $\mathrm{TM} / \mathrm{SPOT}$ bands most closely match in spectral range while they simultaneously give the widest possible spectral separation.

\section{TECHNICAL PROCEDURES}

The images must be matched precisely in order to detect any changes. Therefore, we registered the images using nine control points on rock outcrops, and the SPOT image was matched to the TM image. Because of the difference in pixel size (about $30 \mathrm{~m}$ for the TM image, $20 \mathrm{~m}$ for the SPOT image) the SPOT image was degraded using a $2 \times 2$ digital number (DN) low-pass filter. The SPOT image was then reduced by a factor of 1.5 in resolution. A common sub-area of each image was thereafter selected for analysis (Figs 2 and 3).

We have previously shown (Orheim and Lucchitta, 1988) that taking ratios of satellite bands is a useful technique for extracting information on surface properties because it accentuates the albedo signal by reducing the effects of slopes. Inspection of the images shows that the TM band $4 / 2$ ratio and the corresponding SPOT band $3 / 1$ ratio give good visual separation of blue ice from snow and rock. This result can also be deduced from Ødegaard and Helle (1982), who showed that the pixel values representative of snow, rock and ice are widely separated between the green and near-IR bands.

Information on changes in the registered images can be obtained by selective Principal Component Analysis (PCA). PCA is a statistical technique for selecting the sub-space that contains most of the variance in an image (Haralick and Fu, 1983; Podwysocki and Segal, 1983). If applied to an image of multiple bands, Principal Component 1 (PC1) reflects information common to the bands, which is usually the topography. Principal Component 2 (PC2) shows where

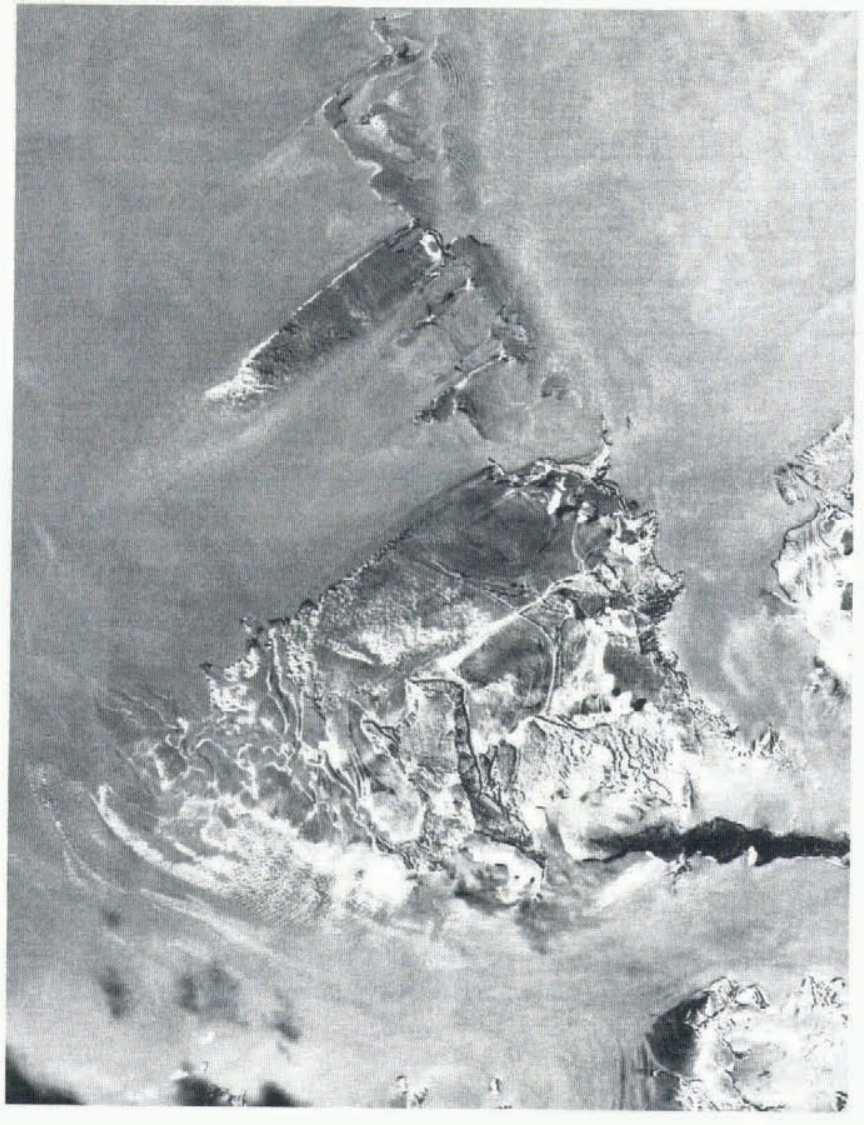

Fig. 4. PC2 image of TM $4 / 2$ and SPOT $3 / 1$ ratios of images shown in Figures 2 and 3 . Most of the light splotches and fine light lines are changes from blue ice in the TM image to snow in the SPOT image. These lines and splotches occur in the blue ice areas associated with the rock outcrops of Jutulsessen in the center and with the mountains near the right margin of the images. The light areas, however, also include changes in shadow, which were longer on the TM image than on the SPOT image. Shadow changes are also reflected in small dark areas where illumination on the TM image changed to shadow on the SPOT image because of shifting sun azimuth. Other light areas (changes from dark to light) are associated with the rock outcrops in the bottom right of the images, and other dark areas (changes from light to dark) with the east-west trending outcrop near the lower right margin. The physical reasons for these changes are not obvious from inspection of the ratio images. Possibly the ratio images contained artifacts resulting from division by very low DN values. Diffuse dark area in lower left is cloud.

bands differ most from one another. On Antarctic images, the difference may reflect differing snow and ice surface properties (Orheim and Lucchitta, 1988).

Chavez and Kwarteng (1989) applied selective PCA on pairs of individual bands to distinguish geologic formations, and they suggested that this technique could also be used to detect temporal changes between images. We have followed this approach by using the band ratios TM $4 / 2$ and SPOT $3 / 1$ as input. By using only two variables, PC2 will show temporal changes on scenes covering the same area and having similar input parameters.

\section{RESULTS AND DISCUSSION}

Figure 4 shows a PC2 image of the selective principal component analysis using ratios from the TM and SPOT images as input. Table I gives the PCA statistics and shows that most of the variance is in $\mathrm{PCl}$, which contains the information that the TM and SPOT ratio images have in common. Even though the information contained in PC2 is much smaller, it is nevertheless substantial. Table I also gives the eigenvector matrix of the PCA. 
TABLE I

Eigenvector matrix

$\%$ variance

$\begin{array}{ll}\text { TM } 4 / 2 & \text { SPOT } 3 / 1 \\ +0.8538 & +0.5206 \\ -0.5206 & +0.8538\end{array}$

95.54

$\mathrm{PC} 1$

$-0.5206$

$+0.8538$

It follows from Table I that the PC2 image is constructed from the following expression:

$$
\mathrm{PC} 2=0.8538 \times \mathrm{SPOT} 3 / 1-0.5206 \times \mathrm{TM} 4 / 2
$$

The image can be interpreted from these parameters. Areas that are light on the TM-ratio image and dark on the SPOT-ratio image (for instance, the clouds in Figure 3) show as dark areas in the PC2 image (Fig. 4). Areas that are dark on the TM-ratio image and light on the SPOT-ratio image (for instance, areas that change from blue ice to snow) show as bright on the PC2 image. Intermediate-grey areas on the PC2 image designate areas. of little change.

The light splotches and fine light lines in Figure 4 show that in general there has been a reduction in blue ice areas from 1985 to 1987 , caused by incursion of snow. Much of this incursion is so subtle that it is only seen after very careful inspection of the colour composites and would be overlooked in a casual analysis. Yet the change is very noticeable in Figure 4 . The ease of recognition illustrates that the PC2 technique is a powerful tool to alert the investigator to changed blue ice conditions.

Some of the reduction in blue ice is associated with narrow, diffuse lines or diffuse patches of snow that appear to be wind drifts covering the blue ice area with thin layers of snow. But other blue ice-to-snow boundaries are sharp and distinct. Figure 5 shows that these boundaries did not change in the two Landsat images TM 5036207394 and TM 5034407520 that were taken nearly three weeks apart, even though wind-related changes in the snow patterns were substantial during that interval (Orheim and Lucchitta, 1988). Thus it appears that these boundaries are fairly permanent features not readily altered by wind-drifted snow. Only ground inspection, however, will verify what constitutes these boundaries. and whether they indeed delineate persistent changes in blue ice extent.

\section{CONCLUSIONS}

We have demonstrated that selective principal component analysis can be applied to detect temporal changes in blue ice extent. We have also shown that (1) this technique can be applied to images from different satellites such as Landsat and SPOT, (2) significant results can be obtained by using band ratios to enhance surface properties, and (3) Principal Component 2 can be used to detect information that differs between two images. Our results suggest that in this part of Antarctica an increase in snow cover over blue ice occurred between 1985 and 1987. One explanation for this change is that the snow accumulation rate was higher in 1987 than in 1985 , but other possible explanations include changed wind patterns. The procedure and the analysis described above should be readily applicable to other pairs of digital image data covering blue ice fields. If the technique is applied repeatedly to many blue ice areas on an Antarctica-wide scale, the transitory effects of local weather changes can be minimized and real trends in blue ice changes may emerge. Detected changes should then not only alert the glaciology community to local mass balance changes, but also give an indication of overall changes that may be related to such global climatic effects as changes in precipitation rate.

\section{ACKNOWLEDGEMENTS}

We gratefully acknowledge substantial help from Jo-Ann Bowell, who processed the images, and from Pat Chavez, who suggested some of the techniques. Image 5034407520 was reproduced by permission of EOSAT, and image 176-680 was reproduced by permission of SPOTIMAGE.

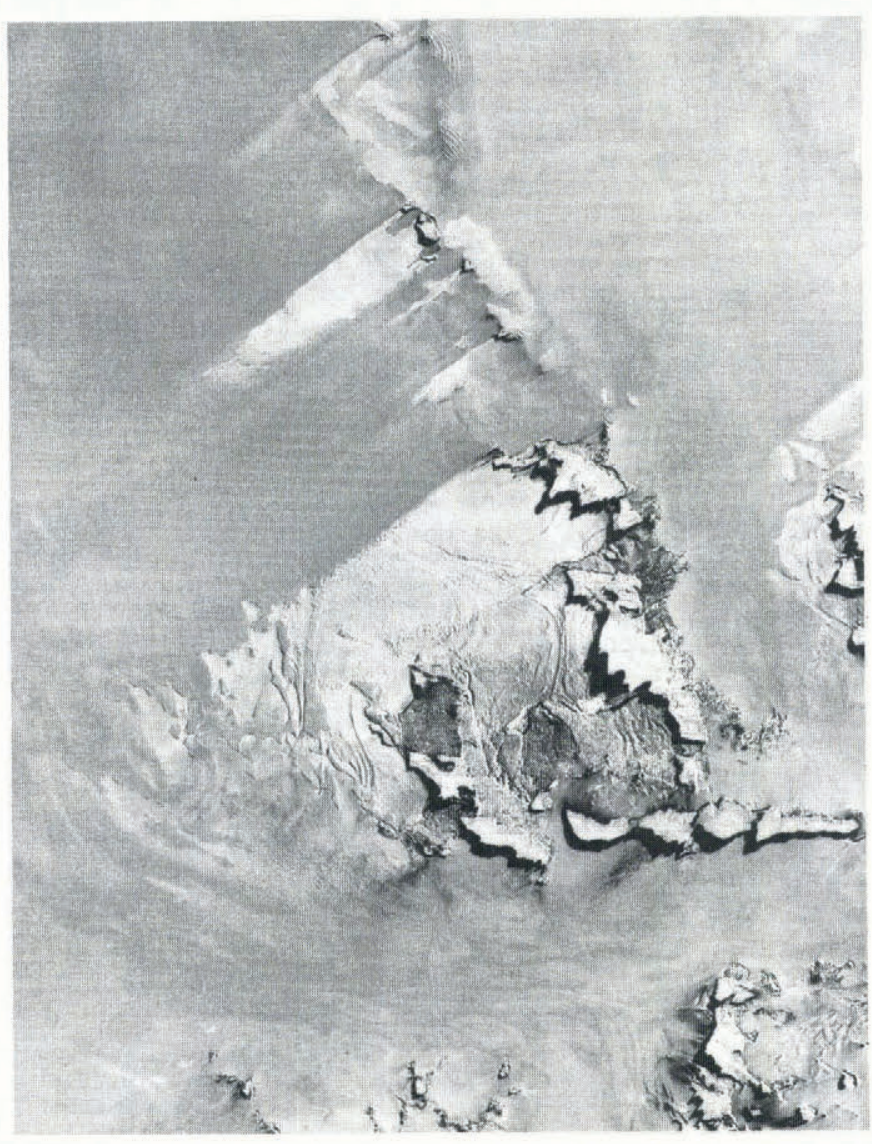

Fig. 5. PC2 image of TM $4 / 2$ ratios of TM scenes recorded on 8 and 26 February 1985. The image shows essentially no change in blue ice extent between these two TM scenes, even though extensive wind-related changes are seen on nearby snow surfaces (Orheim and Lucchitta, 1988). This observation demonstrates that (1) the technique of image matching is adequate to avoid edge-effects around features caused by misregistration, (2) the selective PCA technique highlights real changes between the images, and (3) the studied blue ice fields did not change in spite of variations in local weather conditions over these 18 days.

\section{REFERENCES}

Chavez, P.S., $j r$ and A.Y. Kwarteng. 1989. Extracting spectral contrast in Landsat thematic mapper image data using selective principal component analysis. Photogramm. Eng. Remote Sensing, 55(3), 339-348.

Haralick, R.M. and K.-S. Fu. 1983. Pattern recognition and classification. In Colwell, R.N., ed. Manual of remote sensing. Vol. I. Second edition. Falls Church, VA, American Society of Photogrammetry, 793-805.

Ødegaard. H. and S. Helle. 1982. Polar mapping using Landsat data. Final report. Oslo, IBM and Norsk Polarinstitutt.

Orheim, O. 1977. Global glacier mass balance variations during the past 300 years. In Dunbar, M.J., ed. Polar oceans. Calgary, Arctic Institute of North America, 667-680.

Orheim, O. and B.K. Lucchitta. 1988. Numerical analysis of Landsat thematic mapper images of Antarctica: surface temperatures and physical properties. Ann. Glaciol., 11, 109-120.

Podwysocki, M.H. and D.B. Segal. 1983. Selected methods for digital processing of multispectral scanner data for mapping lithologic units. In Colwell, R.N., ed. Manual of remote sensing. Vol. 2. Second edition. Falls Church, VA, American Society of Photogrammetry, 1744-1757.

Schytt, V. 1961. Glaciology II. Blue ice-fields, moraine features and glacier fluctuations. Norwegian-BritishSwedish Antarctic Expedition, 1949-1952. Scientific Results, 4E, 183-204. 
Swithinbank, C. 1988. Satellite image atlas of glaciers of the world. Antarctica. U.S. Geol. Surv. Prof. Pap. 1386-B.

Takahashi, S., R. Naruse, M. Nakawo, and S. Mae. 1988. A bare ice field in east Queen Maud Land, Antarctica, caused by horizontal divergence of drifting snow. Ann. Glaciol., 11, 156-160.

Whillans, I.M. and W.A. Cassidy. 1983. Catch a falling star: meteorites and old ice. Science, 222, 55-57.

Williams, R.S., jr, T.K. Meunier, and J.G. Ferrigno. 1983. Blue ice, meteorites and satellite imagery in Antarctica. Polar Rec., 21(134), 493-496.

Yoshida, M., H. Ando, K. Omoto, R. Naruse, and Y, Ageta. 1971. Discovery of meteorites near Yamoto Mountains, East Antarctica. Antarct. Rec. 39, 62-65. 